\title{
Development of the Cooperative Intelligent Transport System in Thailand: A Prospective Approach
}

\author{
Aroonrot Choosakun (D), Yaowapa Chaiittipornwong (D) and Chunho Yeom * (D) \\ International School of Urban Sciences, University of Seoul, Seoul 151-742, Korea; aroonroł@gmail.com (A.C.); \\ cgyaowapa@gmail.com (Y.C.) \\ * Correspondence: chunhoy7@uos.ac.kr; Tel.: +82-2-6490-5154
}

Citation: Choosakun, A.;

Chaiittipornwong, Y.; Yeom, C.

Development of the Cooperative Intelligent Transport System in Thailand: A Prospective Approach. Infrastructures 2021, 6, 36. https:/ / doi.org/10.3390/infrastructures6030036

Academic Editor: Isam Shahrour

Received: 22 January 2021

Accepted: 3 March 2021

Published: 7 March 2021

Publisher's Note: MDPI stays neutral with regard to jurisdictional claims in published maps and institutional affiliations.

Copyright: (c) 2021 by the authors. Licensee MDPI, Basel, Switzerland. This article is an open access article distributed under the terms and conditions of the Creative Commons Attribution (CC BY) license (https:// creativecommons.org/licenses/by/ $4.0 /)$.

\begin{abstract}
Smart mobility is becoming an alternative technology of transportation development for today and the future. Thailand has applied the intelligent transport system (ITS) to improve traffic and transport services. The success of the project is generally dependent on collaboration between private, public, and governmental agencies in policymaking and planning, coupled with an inclusive agreement and technological knowledge in the field. This study argues that Thailand's automatic transportation has been successful because of cooperative-ITS (C-ITS). This study explores the evidence-based cases of ITS development from six areas, Singapore, South Korea, Japan, China, the European Union, and the United States of America, to explain how the C-ITS conditions support the success of ITS. The study uses the SWOT (Strength, Weakness, Opportunity, Threat) and TOWS (Threat, Opportunity, Weakness, Strength) analysis matrix to identify influential factors from the six-area cases and compare them to Thailand. The authors identified seven components that relate to the success of Thailand's C-ITS. These include: (1) Pragmatic policy for pilot project implementation; (2) close cooperation among stakeholders; (3) working criteria for C-ITS development; (4) architecture of standard and framework; (5) share of lessons learned about current technology; (6) capability of C-ITS deployment; and (7) a clear statement of data exchange and sharing. These findings represent both the threat and opportunity for traffic and transport improvement in Thailand through the C-ITS approach.
\end{abstract}

Keywords: cooperative-ITS; intelligent transport system; smart mobility; Thailand traffic and transport services

\section{Introduction}

Smart mobility, which is one important component of smart city development, refers to the coordination of goods, people, and transport with information and technology to enable efficient mobility in the area [1,2]. Nowadays, digital technological advancement has enabled the development of automatically smarter transportation systems. The advantages of technological innovation promote the transformation of the transportation system into smart mobility that is more efficient, intelligent, and environmentally friendly. This is regarded as an intelligent transport system (ITS) that provides a variety of solutions for emergency, safety, traffic management, information provider, and road-vehicle collaboration [3]. Many countries in Asia, such as Singapore, South Korea, Japan, and China, have used ITS to achieve smart mobility, as well as some countries from the European Union (EU) as well as the United States of America (USA). They have strengthened the ITS approach by adapting it to a cooperative-ITS (C-ITS) system [4]. The system can be categorized into four sections: (1) Drivers, (2) other road users, (3) public agencies, and (4) service providers, consistent with the cooperative patterns of vehicle-to-vehicle (V2V), vehicle-to-infrastructure (V2I), and vehicle-to-everything (V2X) technology [5].

Thailand's first ITS Master Plan was formulated in 2014 and the latest in 2019. The ITS development plan that has set up projects that will allow Thailand to achieve smart 
transport by 2027. We classify our ITS into six systems: The area traffic control system, commercial vehicle operations, travel information system, advanced public transportation systems, automation traffic enforcement, and electronic toll collection [6]. We also transformed the ITS to the C-ITS, which is used to achieve smart mobility. The C-ITS covers the roles of all related agencies in initiating harmonized specifications, learning and utilizing the technologies, sharing and transferring technological knowledge, and building cooperation among stakeholders [7]. To provide recommendations for Thailand's C-ITS development, we review the successful cases from the other countries using the index of C-ITS development procedure.

\section{Objectives and Methods}

This study contributes to the drawing of an appropriate approach to C-ITS development in Thailand. The study used the successful principles of C-ITS development in Singapore, South Korea, Japan, the Republic of China, the USA, and the EU as the evidence-based cases. These principles were examined through document analysis, and then categorized and compared to analyze the internal and external factors of C-ITS development in Thailand for integration into the SWOT (Strength, Weakness, Opportunity, Threat) and TOWS (Threat, Opportunity, Weakness, Strength) analysis matrix format. The final result was a feature of information about C-ITS development potential in the context of Thailand.

\section{Analysis and Results}

This section is divided into four parts: (1) Current C-ITS development details in Thailand and the other six areas, (2) success factors of C-ITS development in the six countries by category, (3) factor comparison of C-ITS development between Thailand and the other case studies, and (4) the matrix of SWOT and TOWS analysis for Thailand C-ITS development. The results are reported accordingly.

\subsection{Current C-ITS Development}

\subsubsection{Thailand}

In 2019, Thailand's ITS Development Master Plan was approved by the Commission for the Management of Land Traffic. In the same year, the ITS Committee was established to regulate and drive the ITS Master Plan. The goal of the Master Plan is to enhance ITS as a tool for smart transport development in Thailand. The plan was defined for 10 years, from 2018-2028. It was divided into two levels, the national level and the Bangkok and Metropolitan Region level, under three phases of development, which are short-term (3 years), intermediate-term ( 2 years), and long-term ( 5 years). It defines the policy and plan for the responsible agency to implement nonduplicative projects. According to the plan, the transport system will be strengthened by the smart systems of law enforcement, traffic information communication, public transport management, and logistic process to be more effective, inclusive, safe, and environmentally friendly. Besides, the project of the connected vehicle, $\mathrm{V} 2 \mathrm{~V}$, and $\mathrm{V} 2 \mathrm{X}$ was designed for a prefeasibility study of C-ITS implementation in Thailand [6].

In August 2020, the cabinet approved the 5-G Action Plan that utilizes 5G technology to elevate social and economic growth. The development of a connected vehicle was therefore set as the project platform to determine a flagship of this Action Plan [8]. Besides the Ministry of Transport and the Ministry of Digital Economy and Society, there are some more research institutes and private sectors working on C-ITS and smart mobility development in Thailand, such as the ITS Lab of the National Electronics and Computer Technology Center (NECTEC), ITS Thailand, and TOT Public Company Limited [9-11]. The relation of ITS development stakeholders in Thailand is presented in Figure 1. The prefeasibility study of connected V2V and V2X in accordance with ITS Master Plan evaluated by OTP has not been established due to the capability of the concerned parties. One more constraint is the barrier of automatic real-time integrated data exchange among all 
data centers, because there is no standard of data transfer or isolated information center functioning as an ITS integration center. Only the Public Transport Information Standard exists, which is reviewed by the national standard committee and used as the national standard [12].
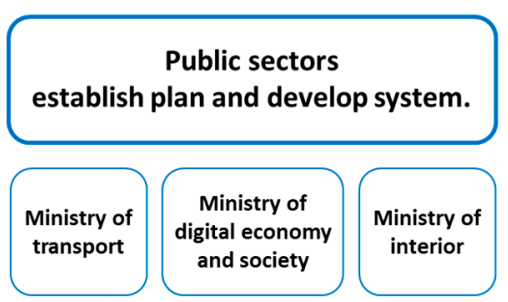
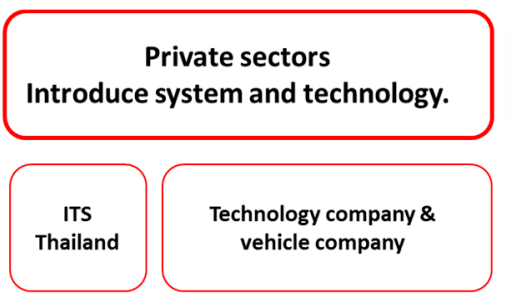

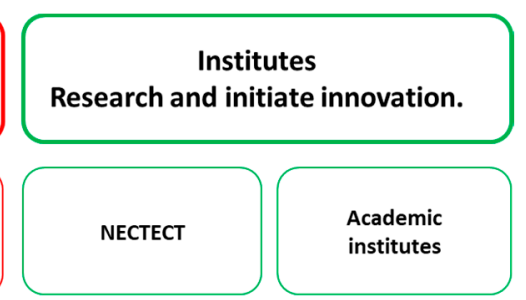

Figure 1. Organization on intelligent transport system (ITS) development in Thailand.

\subsubsection{Singapore: The CETRAN Project and C-V2X Technology}

Due to the socioeconomic landscape of Singapore, with its scarcity of land, ITS significantly enhances the overall commuting experience of travelers. "Moving towards a more connected and interactive land transport community" was launched as an ITS vision in shaping the country into an integrated, vivacious, and more inclusive community. The Singapore-ITS strategic plan was first developed by the Land Transport Authority (LTA) and the Intelligent Transportation Society of Singapore (ITSS) through the campaign of "Smart Mobility 2030" [13]. The strategies can be divided into three key categories: The implementation of innovative and sustainable smart mobility solutions, ITS standard development and adoption, and the establishment of close partnerships and cocreations.

Under the plan, the Committee on Autonomous Road Transport (CARTS) and the Singapore Autonomous Vehicle Initiative (SAVI) were formed to involve the public and private sectors such as the JTC Corporation (JTC); the Agency for Science, Technology and Research (A*STAR); and the Telecommunications Standards Advisory Committee (TSAC) for setting the Dedicated Short-Range Communications (DSRC) standards supportive to the ITS development [14,15]. In 2016, Nanyang Technological University (NTU) started the Centre of Excellence for Testing \& Research of AVs (CETRAN) project to establish a national standard of autonomous vehicle testing and certification [16]. As part of NTU's plan, a self-driving golf cart and electric shuttle around the university were arranged for the trial of two full-sized autonomous buses [17]. Moreover, NTU, together with M1 Limited (M1), has integrated 5G technology into the communication device of cellular vehicle-to-everything (C-V2X), which permits industry partners to deploy 5G-connected mobility in traffic areas regarding crash avoidance, real-time traffic routing, and network security. The C-V2X equipment is installed in shuttle buses and autonomous vehicles to enable vehicle localization tests in a real-world environment [18]. The attempts seek to enrich the Singapore C-ITS.

\subsubsection{South Korea: C-ITS on Daejeon-Sejong Expressway}

In 2013, the C-ITS Master Plan, including C-ITS infrastructure implementation and onboard unit installation, was established to meet the target of zero traffic accidents by 2030 [19]. The pilot project of C-ITS at Daejeon-Sejong expressway was initiated to promote the system of road accident prevention. The project was designed through the cooperation of the Ministry of Land, Infrastructure, and Transport (MOLIT); Korean Expressway Cooperation (KEC); and Korea-ITS. Four main tasks covering infrastructure development, service, technology verification, system maintenance, and standard establishment were performed to assemble project accomplishments [20]. The task service is categorized into seven sections: Primary information collection and providing, toll collection, safe driving support, intersection-traffic safety support, public-transportation safety support, pedestrian care, and accident prevention between vehicles. 
Besides these four parties, the National Research and Development Institute, Korean Transport Institute (KOTI), Korea Institute of Construction Technology (KICT), and Korea Research Institute for Human Settlements (KRIHS) are working on ITS research and development to support policy and planning. Korea-ITS is the most important player to establish the ITS standard, provide a workshop for ITS specialists, and facilitate dealings between private and public agencies [20]. Korea-ITS has a responsibility to engage in activities that meet both local and international standards, operate general assembly for ITS standards, and act as a part working with the Korean Agency for Technology and Standards. Consequently, all stakeholders are involved in the process of national standards of ITS development [21].

\subsubsection{Japan: A New C-ITS on the "ETC2.0" Project}

In the late 1990s, the Japanese government and a nonprofit organization collaborated on ITS development, starting from information and functions clarification by formulating the ITS architecture [22]. As a result, they established 9 development areas, 21 user services, and 172 user subservices [23]. Once the Japan C-ITS system was established, the Vehicle Infrastructure Communication Systems (VICS) was applied with the radio frequency at 2.4 GHz to communicate the In-Vehicle Information (IVI) [24].

In 2014, Japan-ITS entered a subsequent stage where the Ministry of Land, Infrastructure, Transport, and Tourism (MLIT) set out a new C-ITS project, namely "ETC2.0." This development provided two more patterns of data communication: V2I and V2V. The ETC2.0 requires higher capacity and bidirectional capabilities of the active 5.8-GHz Dedicated Short-Range Communication (DSRC) to increase the information retrieval capacity and devise simultaneously data prior collected as the probe data. The data were turned into accurate and detailed traffic congestion information, resulting in multiple running V2I applications. These features became the dynamic route guidance on an expressway in the entire Tokyo metropolitan. Two years later, the joint public-private research on the next generation of V2I was started by the National Institute for Land and Infrastructure Management (NILIM). The study covered three main topics: Roadside service, onboard-vehicle service, and a common platform supporting safe driving and smoother road traffic.

In 2015, it became obvious that several types of C-ITS, coupled with innovations in traffic issues, would be speedily developed and released in Japan. Anticipated is the automated driving car after 2020. This technology deserves a semi-autopilot system that is automated either for driving on an expressway or getting mobility service by a no-drivercar in a limited area. It is concurrent to the Public-Private ITS Initiatives and Roadmap 2016 dealing with technology improvement which was beneficial for, and benefitted from, public services and private companies.

\subsubsection{Republic of China: LTE and 5G-V2X}

The Republic of China initiated the C-ITS to elevate the connected-communication system of vehicle-to-any. In the short term, the expressway information for safety and traffic management is disseminated, while the encouragement of roadside and in-vehicle equipment collaboration is set for the long term [25]. Standard and specification of V2X development in China are promoted as government policy. First, the Industry Development Special Committee was established to be responsible for V2X development. The related ministries expressed their policy to support V2X about the standard, technology, application, and service. National regulators such as the Frequency Management Regulations for the Intelligent Connected Vehicles (Interim), Specifications of Automated Driving Tests (Trial) on a public road, and Technical Guide for Construction of Automated Driving Closed Test Site (Provisional) are responsible for defining the standard, specific, and fundamental requirement of connected vehicle development. Currently, some closed areas in various cities such as Beijing, Shanghai, and Wuxi are used to implement a test-based V2X and automated driving technology. Another project is to improve more than 10 smart roadside units for smart highways [26-28]. 
The development of V2X can be classified into eight fields: Information service application, safety application, transport efficiency improvement, vehicle platoon, remote driving, sensor extension, and advanced driving [26]. In terms of the C2X industry, its chain mainly includes communication chipset, module, terminal, a V2X protocol stack, vehicle, intelligent road, and infrastructure. They function as the support agent for V2X development. Companies such as Huawei, Datan, and Quectel are advancing their technology to be compatible and harmonized with 5G technology [29].

\subsubsection{The United States of America: V2X and C-V2X}

Over the past several years, the United States Department of Transportation (USDOT) and its operating administration have engaged in numerous activities of connected vehicles devoted to the communication patterns of V2V, V2I, and V2P, which are collectively known as V2X. The technology of V2X has the potential of improving transportation safety and mobility benefits, both on their own and as a complementary technology if combined with in-vehicle sensors. The technology also supports the integration of automated vehicles into other innovative applications [30]. USDOT has routinely revised their regional ITS architecture, namely the Architecture Reference for Cooperative and Intelligent Transportation (ARC-IT). ARC-IT creates a broadly cross-sectional ITS community, comprising experts from transportation professionals and system engineers, system developers, technology specialists, and consultants [31].

In 2017, the USDOT released new federal guidance of the Automated Driving System (ADS) as a vision of Safety 2.0. A data roundtable on automated vehicle safety was arranged to bring together over 60 participants from federal, state, and local governments; the private sector; a nonprofit organization; and a research center to discuss data exchange for safe deployment of an automated vehicle. The initial feedback involved the principle of data exchange. Additionally, a framework to accelerate the safe deployment of automated vehicles and an essential step in developing a shared understanding of collected and exchanged data among stakeholders were discussed. The principles also extended to all on-road transportation systems, as they were based on a diverse set of principles from all stakeholders focused advancing multimodal safety, reducing policy uncertainty, and outlining the work process of USDOT [32]. For adaptation to future transportation, the Automated Vehicles 4.0 (AV 4.0) was created in relation to the Automated Driving Systems 2.0 (ADS 2.0) and AV 3.0 [33]. The pilot undertaking covered the facility operation and automated vehicles at rail crossings. Moreover, the National Highway Traffic Safety Administration (NHTSA) has the authority to establish the Federal Motor Vehicle Safety Standards (FMVSS) for ADS-equipped vehicles. The information and communications technology (ICT) standards were set up for its subsystem and technology before integration into the overall automation system, even the surface transportation system [34].

The pilot project of autonomous and connected vehicle infrastructure cooperation for safety was developed in Fremont, California [35]. The project exhibited advanced reporting technology in the ADS vehicle and the location of an infrastructure object representing safety, traffic signal status between the infrastructure and the ADS, the reliability of phase-detection against time reporting, and the reliability of the traffic signal against connected-freight priority over $4 \mathrm{G}$ or LTE. The direct and indirect benefits include decreased travel time, congestion reduction, reduced fuel consumption, manufacturing performance improvement, and economic growth. The project also brings technology and logistics solutions beneficial for other commercial vehicles and those confronting similar transportation issues. Also, the Cellular Vehicle-to-Everything (C-V2X) technology, which is behind the 5G Automotive Association (5GAA) in the USA, was rolled out to increase safety for drivers, pedestrians, and cyclists across the state. The development is consequently aligned with 5GAA's Visionary 2030 Roadmap [36]. 


\subsubsection{European Union: C-Roads Platform}

In 2016, the international collaboration of the C-Roads initiative was introduced as a linkage of ITS development for the automatic system across countries in the EU, where it covers a total of 18 core members [37]. This was achieved using common-technical specification, policymaking, and developing a system of test basis. In 2019, a total of 43 cities and 100,000 km in EU were covered by the C-ITS service. Five working groups, consisting of the Organization Aspect, Evaluation \& Assessment, Technical Aspect, Urban C-ITS Harmonization, and Digital Transport Infrastructure, were set for this task $[38,39]$. The factors for the success of C-ITS in EU are communication harmonization and the international cooperative procedure. The ETSI ITS-G5 and operational cellular network were combined accordingly, with the support, participation, and follow-up from the European Commission (EC) and the Innovation and Networks Executive Agency (INEA).

Today, the 25 DAY 1-Service and the C-Roads platform are widely applied in various applications, such as emergency brake lights in Spain and Portugal; emergency vehicle access in the Czech Republic, Spain, and Portugal; and priority request for traffic signal via designed vehicles in France, Austria, Hungary, and Italy. The common standard harmonization of different components is also essential to C-ITS implementation. However, in 2010, to solve some conflicts among existing ITS standards, European Standardization Organizations (ESOs) were requested to function as developers of minimum and consistent C-ITS standards used by vehicle manufacturers and responsible ITS implementation sectors $[39,40]$.

\subsection{Success Factors of C-ITS Development by Category in the Six Areas}

Although these selected six area-cases have different general ITS development stage scales, they have common supportive factors to convey C-ITS development. China can be classified as a single system, and Singapore is partially integrated, whereas government pushes innovative technology and standards forward. South Korea, Japan, the USA, and the EU are in a fully integrated system where the basic component is ready to step forward to the C-ITS [41]. Public, private, and research institutes cooperate excellently to initiate the C-ITS pilot project. Countries with a prompt to release a vehicle to fit with C-ITS, such as South Korea, Japan, the Republic of China, and the USA, have developed a practical pilot project in the C-ITS platform. Referring to the evidence-based cases of C-ITS employment from the six areas, the common practices found by category as shown in Table 1. Common practices involve five aspects covering policy, pilot project, standard and framework agreements, collaboration among related agencies, and the research and development sector (R\&D).

\subsection{Factor Comparison of C-ITS Development between Thailand and the Case Studies}

The situation between Thailand and the case studies were compared as detailed in Table 2. We aimed to compare the main factors which affect the deployment of ITS utilizations. According to Table 1, the summarization of the driving factors of C-ITS activity presents that all the advanced C-ITS developments have clear policy announcements and have deployed the pilot project implementation based on the agreements and standards among stakeholders. The support from all related agencies, public sectors, private sectors, and research sectors is another explicit means causing the innovation of C-ITS development. Nevertheless, Thailand has all basic ITS systems, but the general platform of C-ITS standard has not been stated. Although advanced technology is introduced to be utilized in any system, the integrated and integrated approach is difficult to initiate. Thus, when the situation in Thailand was compared to the six area-based cases, four out of five aspects presented a gap in C-ITS development in Thailand. The initiation of the ITS Master Plan is only one similarity explaining the progress of C-ITS development in Thailand that implies our intangible effort and possibly implies inefficient attainment. The rest is certainly required for a professional working system of infrastructure project development. Otherwise, the project is too risky to absorb. 
Table 1. Common practice for cooperative-ITS (C-ITS) development in the six-case study.

\begin{tabular}{|c|c|c|c|c|c|}
\hline Case Studies & Policy & Pilot Project & $\begin{array}{l}\text { Standard and } \\
\text { Framework }\end{array}$ & Collaboration & R\&D \\
\hline Singapore & $\begin{array}{l}\text { The Smart Mobility } \\
2030 \text { strategic plan } \\
\text { was issued in } 2014\end{array}$ & $\begin{array}{l}\text { The CETRAN project } \\
\text { was launched in } 2016\end{array}$ & $\begin{array}{l}\text { TSAC Working } \\
\text { Group for ITS } \\
\text { Standard } \\
\text { Development }\end{array}$ & $\begin{array}{l}\text { NTU, Institute } \\
\text { Research, Private } \\
\text { Companies }\end{array}$ & $\begin{array}{c}\text { Testing \& Research of } \\
\text { AVs at NTU }\end{array}$ \\
\hline South Korea & $\begin{array}{c}\text { The C-ITS Master } \\
\text { Plan was established } \\
\text { in } 2013\end{array}$ & $\begin{array}{l}\text { The Daejeon-Sejong } \\
\text { expressway was } \\
\text { initiated in } 2014\end{array}$ & $\begin{array}{l}\text { ITS Standard by ITS } \\
\text { Korea }\end{array}$ & $\begin{array}{c}\text { MOLIT, KEC, ITS } \\
\text { Korea }\end{array}$ & $\begin{array}{l}\text { National R\&D } \\
\text { Institution }\end{array}$ \\
\hline Japan & $\begin{array}{l}\text { ITS Promotion } \\
\text { Guidelines was } \\
\text { released in } 2004\end{array}$ & $\begin{array}{c}\text { The C-ITS project } \\
\text { "ETC2.0" was launched } \\
\text { in } 2014\end{array}$ & $\begin{array}{l}\text { ITS Architecture and } \\
\text { Common Platform } \\
\text { for C-ITS }\end{array}$ & $\begin{array}{c}\text { Working group and } \\
\text { Public-Private ITS } \\
\text { cooperation }\end{array}$ & $\begin{array}{c}\text { Public-Private ITS } \\
\text { Research }\end{array}$ \\
\hline Republic of China & $\begin{array}{c}\text { The government } \\
\text { policy was developed } \\
\text { issued in } 2017\end{array}$ & $\begin{array}{l}\text { Autonomous cars test } \\
\text { in Beijing, Shanghai, } \\
\text { Wuxi, etc. started in } \\
2017\end{array}$ & $\begin{array}{l}\text { National Standard } \\
\text { for V2X }\end{array}$ & $\begin{array}{l}\text { MOT, MIIT, Private } \\
\text { Companies }\end{array}$ & $\begin{array}{l}\text { R\&D Institute and } \\
\text { Cooperation with } \\
\text { International } \\
\text { Agencies }\end{array}$ \\
\hline USA & $\begin{array}{l}\text { The guidance of the } \\
\text { Automated Driving } \\
\text { System (ADS) was } \\
\text { released in } 2017\end{array}$ & $\begin{array}{l}\text { AV \& CV infrastructure } \\
\text { cooperation for safety } \\
\text { was developed in } 2020\end{array}$ & $\begin{array}{c}\text { ARC-ITS } 9.0 \& \\
\text { Prepare for AV } 3.0\end{array}$ & $\begin{array}{l}\text { Public, Private, and } \\
\text { research center }\end{array}$ & $\begin{array}{c}\text { ITS Joint Program } \\
\text { Office } \\
\text { US DOT }\end{array}$ \\
\hline European Union & $\begin{array}{c}\text { The C-Roads } \\
\text { platform was } \\
\text { introduced in } 2016\end{array}$ & $\begin{array}{l}\text { The crossing site testing } \\
\text { was deployed in } 2019\end{array}$ & $\begin{array}{l}\text { C-ITS EU Standard } \\
\text { and documents }\end{array}$ & $\begin{array}{l}\text { EU Members and } \\
\text { others }\end{array}$ & $\begin{array}{l}\text { Workshop and } \\
\text { Seminar }\end{array}$ \\
\hline
\end{tabular}

Table 2. Comparison of C-ITS development between Thailand and the six-case study.

\begin{tabular}{cclll}
\hline Topic & & \multicolumn{1}{c}{ Thailand } & \multicolumn{1}{c}{6 Case Studies } \\
\hline A policy of Smart Mobility Development & $\bullet$ & ITS Master Plan Establishment & $\bullet$ & ITS Master Plan Establishment \\
\hline Pilot Project of C-ITS & $\bullet$ & Not yet implemented & $\bullet$ & Practical pilot projects implemented \\
\hline $\begin{array}{c}\text { Architecture for Standard and } \\
\text { Framework }\end{array}$ & $\bullet$ & $\begin{array}{l}\text { No official architecture } \\
\text { Public Transport Information } \\
\text { Standard resumed as the relevant } \\
\text { standard }\end{array}$ & $\bullet$ & $\begin{array}{l}\text { Both national architecture and } \\
\text { standards of C-ITS are available at } \\
\text { the national reference }\end{array}$ \\
$\begin{array}{clll}\text { Stakeholder Collaboration and } \\
\text { Regulation }\end{array}$ & $\bullet$ & $\begin{array}{l}\text { ITS Committee Establishment } \\
\text { Fragmented inputs }\end{array}$ & $\bullet$ & $\begin{array}{l}\text { Avail of leading agency for ITS } \\
\text { development } \\
\text { C-ITS working group } \\
\text { Building public-private cooperation }\end{array}$ \\
\hline R\&D & $\bullet$ & $\begin{array}{l}\text { The interest of some academic } \\
\text { institutes and generally }\end{array}$ & $\bullet$ & $\begin{array}{l}\text { A taskforce of the Research and } \\
\text { Development Institute }\end{array}$ \\
\hline
\end{tabular}

\subsection{Matrix of SWOT and TOWS Analysis for Thailand C-ITS Development}

The matrix of SWOT and TOWS analysis was applied to refine the prospective approach for C-ITS development in Thailand. Internal factors of strength (S) and weakness $(\mathrm{W})$ and external factors of opportunity $(\mathrm{O})$ and threat $(\mathrm{T})$ were investigated to represent Thailand's situation. The findings were then examined together with the strategies and supportive factors from the C-ITS successes in the six countries referred to in this paper as the evidence-based cases. The six-area case was itemized as a "case study" under the opportunity factor.

For internal factors, as Thailand has started to develop ITS for many years, all related agencies that already operate the ITS system, including the approval of the Master Plan, are processing practical projects and will be evaluated the outcome by the committee. However, without an integrated platform and architecture, the responsible agencies effectively elaborated the cooperative system. Moreover, the capability building of the representatives in each organization is one of the major issues, because they have consulted to develop the system. The knowledge transferring program is not effective enough to maintain and 
evaluate more advanced systems on its own. In terms of external factors, the national policy in Thailand is now focusing on and encouraging all government offices to apply advanced technology to support and enhance the government service platform. The countries with advanced C-ITS development, such as the EU, Japan, and Korea, have issued an advanced technology workshop on ITS development to share the experience. Although the research sectors and private sectors in Thailand have also paid more attention to cutting-edge technology applications in transport and traffic area, the contradiction of open and sharing data and data privacy obstructs integrated data restriction. In terms of vehicle's standard on fitting C-ITS development, the private sectors have not acknowledged clear objectives and goals of the policy on C-ITS development. Thus, there is a difficult decision to make on investing in automotive vehicles in Thailand.

According to the summarization of success factors in Table 1 and the gap comparison in Table 2, the proposal of appropriate procedure to urge C-ITS development in Thailand is gathered with the strength of the six area case studies to figure out the development gap fulfillment. By matching the strength and opportunities, the existing ITS should be enhanced with advantageous technology to reach the objectives of the Master Plan. The opportunities from the lessons learned and the research capability can overcome the weakness of the lack of knowledge. Formulating the architecture and standard will become a base platform of C-ITS development. As the committee has been set, the responsible agencies should drive the unclear development of the open data policy. For the support of professional skills, the knowledge transfer and workshop should elevate sustainable capability development. Finally, the appropriate features for Thailand's C-ITS development are grouped and displayed in Table 3.

Table 3. Result of SWOT (Strength, Weakness, Opportunity, Threat) and TOWS (Threat, Opportunity, Weakness, Strength) analysis for C-ITS development in Thailand.

\section{Opportunities (O) \\ The national policy supports technol- ogy and innovation development \\ - Advanced technology is available to utilize in the current system \\ Lessons learned and case studies from other countries \\ ITS Research Institutes (i.e., NECTEC, ITS Thailand, TOT) are available and prompt to cooperate with the public sector. \\ - International collaboration is now in- terested in providing workshops and knowledge sharing}

\section{Threats (T)}

- Advanced technology introduced nowadays is changed and updated all the time

Restriction of data exchange between public and private sectors

A standard of automotive vehicles in Thailand

\section{Internal Factors}

\section{Strengths (S)}

ITS Master Plan and 5G Action Plan is established as a guideline of development Existing ITS system and equipment in six categories, and the responsible agencies have experience and basic knowledge of ITS development

ITS committee and the responsibility of ITS deployment is established

\section{Weaknesses (W)}

Non-ITS architecture and standard cause an integrated, incomplete system Lack of capability building in advanced system enhancement

\section{WO}

SO

Proposing the pilot project according to the plan and policy

Enhancing existing ITS with advanced technology

ITS Committee setups with the C-ITS working group to examine the pilot project

\section{ST}

Maintenance and adjustment of an existing system for new technology

Applying some unchanged resources from related stakeholders

Initiating clarification for using open and privacy data among public and private sectors

Provide clearer objectives and policy on vehicle transition to C-ITS

\section{WT}

Performing knowledge transferring from institutes or professionals Indicating officers to attend workshops or seminars related to C-ITS development 


\section{Discussion}

In concordance with SWOT and TOWS analysis to designate C-ITS development guidance in Thailand, the set of strategies and actions can be stated as below:

- The responsible agency that conducts the ITS Master Plan has to address C-ITS development's firm policy to direct the initiation of the pilot project of C-ITS development and its timely implementation.

- ITS committee meetings should be scheduled and should continue to strengthen cooperation among stakeholders that eventually leads to project evaluation and followup actions.

- The working group of C-ITS development established by the ITS Committee has to perform as a leading unit and steering group of C-ITS development in Thailand. The group members should come from all stakeholders related to Thailand's C-ITS development and should be responsible for creating a convenient and comfortable platform for communication and coordination.

- Architecture for the standard and framework of C-ITS development has to be designed, concluded, and agreed upon by all stakeholders. The architecture is to formulate the essential requirement and specifications. The architecture also implies the communication system, data exchange, and sharing condition for all major components of C-ITS implementation, including the vehicle's standard to perform the safety issues.

- Lessons learned should be integrated into current technology knowledge before applying and utilizing them for existing system improvement. In turn, C-ITS development in other countries should be followed to understand new and advanced technology. The advantages will either help to adjust the current system or to reduce the costs of equipment and installation.

- The outcome of cooperation between public and private or academic and business sectors includes a transfer of C-ITS knowledge and related technology, which is possible through the workshop program, which can potentially be a key performance indicator (KPI) for those involved.

- The statement of data exchange and sharing, among other concerns, may be set from the memorandum of understanding (MOU) and memorandum of agreement (MOA) to clarify the differences between open and private data.

- The clear objectives of C-ITS development from the government side must be stated to provide the goal of system development. Thus, the private sectors from the vehicle industry must acknowledge the direction of automotive transition to serve the CITS policy.

In the early stage, the kick of meeting and collaboration among stakeholders should be held to gather the common agreement of C-ITS development to lead the initiation of architecture and standard issues within 1 year. The capability-building and workshop program should be performed regularly to date on innovation and technology changes.

Moreover, system security must be determined carefully because C-ITS development requires wireless connection among vehicles and external components or using an IoT (Internet of Things) system, which may be possibly attacked by hackers and faces security threats, thus impacting system safety [42]. Besides, the cooperative system should include the monitoring system to support the effectiveness evaluation of the installation of the project, such as the number of accidents, the number of public transportation usage, and the degree of traffic congestion. The monitoring system should also provide the tracking of C-ITS development scale in the future.

\section{Conclusions}

Advancements in technology have led to the evolution of ITS to C-ITS, which is more complicated and automatic. Consequently, Thailand has to achieve the goal of a smarter transport system through the strategy of smart mobility. It is, however, obvious that there are numerous threats covering isolated-development, non-standardization, policy-driven, and unclear statements of public and private collaboration. For Thailand to achieve C-ITS 
development for smarter transportation, the following factors must be clarified and figured out: Inclusive policy statement and declaration, pilot project initiation, standard formulation, and interagency collaboration. Not only do the closeup and solid collaborations have a profound impact on Thailand's C-ITS accomplishment, but they also alternate the factor of policy-driven and capability building.

Author Contributions: Conceptualization, A.C. and Y.C.; methodology, A.C. and Y.C.; validation, A.C., Y.C. and C.Y.; formal analysis, A.C. and Y.C.; investigation, A.C. and Y.C.; data curation, A.C. and Y.C.; writing-original draft preparation, A.C. and Y.C.; writing-review and editing, C.Y.; visualization, C.Y.; supervision, C.Y.; project administration, C.Y.; funding acquisition, C.Y. All authors have read and agreed to the published version of the manuscript.

Funding: This work was supported by the National Research Foundation of Korea (NRF) grant funded by the Korea government (MSIT) (grant no. 2019R1C1C1001997).

Conflicts of Interest: The authors declare no conflict of interest.

\section{References}

1. Sujataa, J.; Sakshamb, S.; Tanvic, G.; Shreyad. Developing Smart Cities: An Integrated Framework 6th International Conference on Advances on Computing \& Communications. Procedia Comput. Sci. 2016, 93, 902-909. [CrossRef]

2. Song, H.; Srinivasan, R.; Sookoor, T.; Jeschke, S. Smart Cities Foundation, Principles and Applications, 1st ed.; John Wiley \& Sons, Inc.: Hoboken, NJ, USA, 2017.

3. Xiong, Z.; Sheng, H.; Rong, W.; Cooper, D.E. Intelligent transportation systems for smart cities: A progress review. Sci. China Inf. Sci. 2012, 55, 2908-2914. [CrossRef]

4. Höfs, W.; Lappin, J.; Schagrin, M.; Cronin, B.; Resendes, R.; Hess, S.; Pincus, M.; Schade, H.; Sill, S.; Harding, J.; et al. International Deployment of Cooperative Intelligent Transportation Systems Bilateral Efforts of the European Commission and United States Department of Transportation; ITS-Joint Program Office: Washington, DC, USA, 2012; Available online: https:/ / ec.europa.eu/digital-singlemarket/en/news/international-deployment-cooperative-intelligent-transportation-systems-bilateral-efforts (accessed on 15 November 2020).

5. Lu, M.; Turetken, O.; Adali, O.E.; Castells, J.; Blokpoel, R.; Grefen, P. Cooperative Intelligent Transport Systems Deployment in Europe. In Proceedings of the 25th ITS World Congress, Copenhagen, Denmark, 17-21 September 2018.

6. Office Transport and Traffic Policy and Planning. Executive Summary Report: Study of Intelligent Transport System Development Master Plan in Bangkok Metropolitan Region; Office Transport and Traffic Policy and Planning: Bangkok, Thailand, 2017.

7. Narupiti, S. Smart City (Smart Mobility) in Thailand. Available online: http://itsasia-pacific.com/wp-content/themes/its/ images/CountryReport_Thailand.pdf (accessed on 15 November 2020).

8. Office of the National Digital Economy and Society Commission. Action Plan on the Promotion of 5G Technology Utilization; Office of the National Digital Economy and Society Commission: Bangkok, Thailand, 2020.

9. ITS Lab. Available online: https:/ /its.nectec.or.th (accessed on 14 November 2020).

10. ITS Thailand. Available online: https:/ /its.in.th (accessed on 14 November 2020).

11. TOT. Available online: https://www.tot.co.th/ (accessed on 14 November 2020).

12. Office Transport and Traffic Policy and Planning. Evaluation Report of ITS Action Plan Short Term (3 Years: 2018-2020); Office Transport and Traffic Policy and Planning: Bangkok, Thailand, 2017.

13. CHIN Kian Keong, and Grace ONG. Smart Mobility 2030-ITS Strategic Plan for Singapore. 2015. Available online: https: / / esci-ksp.org/wp/wp-content/uploads/2012/06/J15Nov_p04Chin_SmartMobility2030.pdf (accessed on 10 November 2020).

14. Jaya Shankar, P. Connected Vehicle Technology Development in Singapore. 2015. Available online: https://www.itu.int/en/ITUT/extcoop/cits/Documents/Workshop-201507-Beijing/Presentations/S1P1-Jaya-Shankar.pdf (accessed on 10 November 2020).

15. Info-Communications Media Development Authority. Technical Specification-Dedicated Short Range Communications in Intelligent Transport Systems. 2017. Available online: https://www.imda.gov.sg/-/media/Imda/Files/Regulation-Licensingand-Consultations/ICT-Standards/Telecommunication-Standards/Radio-Comms/IMDA-TS-DSRC.pdf?la=en (accessed on 10 November 2020).

16. Land Transport Authority, Singapore. Singapore Autonomous Vehicle Initiative (SAVI). 2017. Available online: https: / / www.itu.int/en/ITU-T/extcoop/cits/Documents/Workshop-201707-Singapore/010\%20-\%20Alan-Quek-Singapore\%20 Autonomous\%20Vehicle\%20Initiative\%20(SAVI).pdf (accessed on 10 November 2020).

17. Lannuzel, F.X. Smart Mobility: SystemX Contributes to the Future of Mobility in Singapore. 2018. Available online: https://blog. irt-systemx.fr/smart-mobility-systemx-contributes-to-the-future-of-mobility-in-singapore-2/ (accessed on 10 November 2020).

18. ITS International. NTU and M1 to Develop Singapore 5G C-V2X Testbed. 2019. Available online: https://www.itsinternational. $\mathrm{com} /$ its7/news/ntu-and-m1-develop-singapore-5g-c-v2x-testbed (accessed on 10 November 2020).

19. C-ITS (Cooperative Intelligent Transport System. Available online: https:/ / www.c-its.kr/english/introduction.do (accessed on 6 October 2020). 
20. ITS Korea. Right in the Core of ITS. In Proceedings of the 2019 Expert Group Meeting and Regional Meeting on Intelligent Transport Systems (ITS) Development and Operation for Sustainable Transport Systems in Asia and the Pacific, Incheon, Korea, 2-4 April 2019; Available online: https:/ / www.unescap.org/sites/default/files/ITS\%20Korea\%20presentation\%20-\%20Right \% 20in\%20the\%20Core\%20of\%20ITS.pdf (accessed on 6 October 2020).

21. ITS Korea. Available online: https://itskorea.kr/english/main.do (accessed on 6 October 2020).

22. Hasegawa, T. Chapter 5 Intelligent Transport Systems. Available online: https://www.iatss.or.jp/common/pdf/en/publication/ commemorative-publication/iatss40_theory_05.pdf (accessed on 11 November 2020).

23. Japan Society of Civil Engineers and the Asian Civil Engineering Coordinating Council. Intelligent Transport Systems (ITS) Introduction Guide Version 1.1, Japan. 2016. Available online: https://www.jsce-int.org/system/files/ITS_Introduction_Guide_ 2.pdf (accessed on 12 November 2020).

24. Makano, H. C-ITS and Connected Automated Driving in Japan. 2017. Available online: http://www.nilim.go.jp/lab/qcg/ japanese/3paper/pdf/2017_13.pdf (accessed on 12 November 2020).

25. Asian Development Bank. Safety and Intelligent Transport Systems Development in the People's Republic of China; Asian Development Bank: Mandaluyong City, Philippines, 2016.

26. Xiang, D. Update on C-V2X Development in China. In Proceedings of the 5G Automotive Association Connected and Automated Driving Workshop, Berlin, Germany, 23 May 2019; Available online: https://5gaa.org/wp-content/uploads/2019/05/03.Update_on_C-V2X_Deployment_in_China.pdf (accessed on 14 November 2020).

27. Xu, B.; China LTE-V2X Communication Standard Progress. SESEC Special Report. 2020. Available online: https://www.sesec. eu/app/uploads/2020/01/China-C-V2X-(EN).pdf (accessed on 14 November 2020).

28. Dezao, H. ITS in China: Updates \& Future. In Proceedings of the 2019 Expert Group Meeting and Regional Meeting on Intelligent Transport Systems (ITS) Development and Operation for Sustainable Transport Systems in Asia and the Pacific, Incheon, Korea, 2-4 April 2019; Available online: https:/ / www.unescap.org/sites/default/files/Country\%20presentation\%20-\%20China.pdf (accessed on 14 November 2020).

29. Shengbo, Y. Introduction of China C-V2X Industry and Standards. Available online: https://www.itu.int/en/ITU-T/extcoop/ cits/Documents/Meeting-20200909-e-meeting/17R1_CSAE_Status-report.pdf (accessed on 14 November 2020).

30. United State Department of Transportation. Vehicle-to-Everything (V2X) Communications. Available online: https://www. transportation.gov/v2x (accessed on 15 November 2020).

31. United States Department of Transportation. ARC-IT Version 9.0 The National ITS Reference. Available online: https://local. iteris.com/arc-it/ (accessed on 15 November 2020).

32. United State Department of Transport. Roundtable on Data for Automated Vehicle Safety Summary Report; United State Department of Transport: Washington, DC, USA, 2018. Available online: https://www.transportation.gov/sites/dot.gov/files/docs/policyinitiatives/automated-vehicles/304471/av-data-roundtable-summary-report.pdf (accessed on 15 November 2020).

33. United States Department of Transportation. USDOT Automated Vehicles Activities. Available online: https://www. transportation.gov / AV (accessed on 15 November 2020).

34. United States Department of Transportation. USDOT Automated Vehicles Activities. Available online: https://www. transportation.gov/av/3 (accessed on 15 November 2020).

35. City of Fremont Public Works. Automated Driving System Demonstration Grant Submission; City of Fremont Public Works: Fremont, CA, USA, 2019. Available online: https://www.transportation.gov/sites/dot.gov/files/docs/policy-initiatives/automatedvehicles/351536/50-city-fremont.pdf (accessed on 15 November 2020).

36. Zagajac, J.; Mulligan, B.; Misener, J. Update on V2X Communications Development in North America. In Proceedings of the 5G Automotive Association Connected and Automated Driving Workshop, Berlin, Germany, 23 May 2019; Available online: https:// 5gaa.org/wp-content/uploads/2019/05/02.Update_on_C-V2X_communications_Deployment_in_North_America.pdf (accessed on 15 November 2020).

37. Böhm, M. C-Roads-Deployment of C-ITS services Throughout Europe. In Proceedings of the 1st EU-ASEAN Workshop on Intelligent Transport Systems (ITS), Singapore, 24-25 October 2019.

38. C-Road. Available online: https:/ / www.c-roads.eu/platform.html (accessed on 6 October 2020).

39. Böhm, M. C-Roads-The Platform of Harmonised C-ITS Deployment in Europe. Available online: https://www.c-roads.eu/ fileadmin/user_upload/media/Dokumente/C-Roads_fact_sheet_2020.pdf (accessed on 6 October 2020).

40. Festag, A. Cooperative intelligent transport systems standards in Europe. IEEE Commun. Mag. 2014, 52, 166-172. [CrossRef]

41. United Nation ESCAP. Intelligent Transportation Systems for Sustainable Development in Asia and the Pacific. Available online: https: / / www.unescap.org/sites/default/files/ITS.pdf (accessed on 19 February 2021).

42. Hamida, E.B.; Noura, H.; Znaidi, W. Security of Cooperative Intelligent Transport Systems: Standards, Threats Analysis and Cryptographic Countermeasures. Electronics 2015, 4, 380-423. [CrossRef] 